\title{
Psychometric properties of the Persian version of the celiac disease adherence test questionnaire
}

\author{
Zeinab Nikniaz ${ }^{1}$, Mohammad Asghari Jafarabadi ${ }^{2}$, Saeideh Ghaffarifar ${ }^{3}$, Zahra Saeedi ${ }^{4}, Z^{2}$ ahra Akbari Namvar ${ }^{4}$ and \\ Masood Shirmohammadi ${ }^{1^{*}}$
}

\begin{abstract}
Background: A gluten-free diet (GFD) is the only effective treatment for celiac patients and assessing adherence to this diet is important. Celiac disease Adherence Test (CDAT) is a valid English-language questionnaire that is used for assessing the adherence to the GFD. In the present study, we aimed to translate the CDAT questionnaire in Persian and evaluate its validity and reliability.

Methods: In the present cross-sectional study, CDAT was translated and back-translated by three bilingual professional translators. Content validity was evaluated by 12 gastroenterologists and nutritionists. To assess the construct validity, 230 patients with celiac disease were randomly selected from the national celiac disease registry database. Internal consistency of the items and test-retest reliability were assessed by Cronbach's alpha and Intraclass Correlation Coefficient (ICC). To assess the convergent validity of the questionnaire, the correlation coefficient between the CDAT score and anti-tissue transglutaminase immunoglobulin A (anti-t-TG-lgA) titer was assessed.

Results: The content validity index, content validity ratio, and impact score of the Persian version of CDAT (PVCDAT) were $0.97,0.95$, and 4.61 respectively. Three significant factors were extracted and according to the confirmatory factor analysis the three-factor model had adequate fitness (chi-square $p$-value of 0.74 , root mean error of approximation: 0.001 [95\% Cl: 0.001-0.083], comparative fit index: 1, standardized root mean squared residual: 0.04, and coefficient of determination: 0.78 ). The questionnaire had good feasibility with the floor effect of $3.1 \%$ and the ceiling effect of $0.4 \%$. Moreover, it has high internal consistency (Cronbach-alpha: 0.71 ) and test-retest reliability (ICC: 0.78). The correlations between CDAT categories and anti-tTG-IgA categories showed a significant correlation between the two tests $(r=0.53 ; P<0.001)$.

Conclusions: The results of the present study showed that the Pv-CDAT questionnaire with high validity, reliability, and internal consistency can be used for assessing adherence to the GFD in adult celiac patients in Iran.
\end{abstract}

Keywords: Celiac disease, Gluten-free diet, Adherence, CDAT, Validation, Persian

\footnotetext{
* Correspondence: drmasood.shirmohammadi@gmail.com

${ }^{1}$ Liver and gastrointestinal diseases research center, Tabriz University of medical sciences, Tabriz, Iran

Full list of author information is available at the end of the article
}

(c) The Author(s). 2020 Open Access This article is licensed under a Creative Commons Attribution 4.0 International License, which permits use, sharing, adaptation, distribution and reproduction in any medium or format, as long as you give appropriate credit to the original author(s) and the source, provide a link to the Creative Commons licence, and indicate if changes were made. The images or other third party material in this article are included in the article's Creative Commons licence, unless indicated otherwise in a credit line to the material. If material is not included in the article's Creative Commons licence and your intended use is not permitted by statutory regulation or exceeds the permitted use, you will need to obtain permission directly from the copyright holder. To view a copy of this licence, visit http://creativecommons.org/licenses/by/4.0/. The Creative Commons Public Domain Dedication waiver (http://creativecommons.org/publicdomain/zero/1.0/) applies to the data made available in this article, unless otherwise stated in a credit line to the data. 


\section{Background}

Celiac disease $(\mathrm{CD})$ is an autoimmune enteropathy that is associated with gluten intolerance in people with a genetic background [1]. In these patients, even the use of a small amount of gluten protein can damage small intestinal mucosa [2] that is associated with different gastrointestinal and non-gastrointestinal clinical manifestations [3, 4]. A gluten-free diet (GFD) is the only effective treatment for these patients $[5,6]$ and strict compliance to this diet could reverse the symptoms and improve nutritional status $[7,8]$. The result of a systematic review showed that adherence to the GFD was low and it ranged from 42 to $91 \%$ depending on the definition and method of assessment [9]. Assessing adherence to a GFD is methodologically challenging. Different methods such as clinician evaluation, serology tests, or endoscopy with duodenal biopsy histology are used to define the level of non-adherence to the GFD [10]. However, these tests have limitations such as inadequate accuracy, low sensitivity, high cost, and invasiveness. Leffler et al. developed a Celiac Dietary Adherence Test (CDAT) which is the fast, and sensitive method of assessing the adherence to the GFD [11]. This questionnaire has seven items, easy to administer and the validity and reliability of the English version were confirmed [11]. From then, it was used in different studies [12-14] and it has been translated into the Spanish language with appropriate psychometric properties [15].

To the best of our knowledge, CDAT has not been translated to Persian yet and clinician evaluation and serology tests are used in physician's daily practice. However, the accuracy and sensitivity of these tests are questionable. Hence, considering the approved validity of the CDAT questionnaire for use in the evaluation of adherence to GFD [11], in the present study, it was aimed to translate the CDAT questionnaire in Persian and evaluate its validity and reliability.

\section{Methods}

The present explorative cross-sectional study was done from July 2018 to January 2020.

The translation and adaptation were done using the Forward-Backward translation method. For this, at first, the permission of the author of CDAT, Dr. D. A Leffler was taken by Email. Then two translators who were fluent in English independently translated the questionnaire into Persian (forward translation). The two versions were compared and any discrepancies were resolved by discussion and a final translated questionnaire was created. This version of the translated questionnaire was back-translated to English by an independent native English language speaker who was unaware of the English version. This version of the questionnaire was sent to Dr. D. A Leffler to confirm.

\section{Statistical analysis}

We analyzed the data using the IBM@ SPSS $\odot$ Statistics version 20 (IBM@ Corp., Armonk, NY, USA) and STATA version 14 .

\section{Assessment of face validity}

Face validity was assessed by the panel of experts (12 experts) and oral feedback of 15 celiac patients immediately after the completion of the questionnaire. The experts were asked to provide their opinion about the importance of each question on the five-point Likert scale. The impact score (IS) was calculated and the values greater than 1.5 were considered acceptable. According to patients and experts opinion, only the minor change in one item was made.

\section{Assessment of content validity}

The Persian version of the CDAT questionnaire (PvCDAT) (Table S1) was tested for content validity in a group of 12 gastroenterologists and nutritionists. The experts were asked to complete a form to evaluate the simplicity, clarity, relevance, and necessity of each question. After the minor change in one item, the final Persian version of the questionnaire was made. Further, we computed the Content validation ratio (CVR) for each item based on the Lawshe method with the participation of 12 experts. The minimum acceptable level of CVR was 0.56. The content validity index (CVI) was also calculated for each item and the minimum acceptable level of CVI was 0.79 .

\section{Assessment of construct validity}

The construct validity of the questionnaire was assessed through Exploratory Factor Analysis (EFA) and Confirmatory Factor Analysis (CFA).

A total of 230 celiac patients were selected from the celiac disease registry database in East Azerbaijan. The patients were selected randomly using a computer-generated random number. EFA was conducted on 130 patients, and CFA was performed on 100 patients. The inclusion criteria were: age 18-65 years and registration in East Azerbaijan celiac disease registry database.

The patients were asked to complete the Pv-CDAT questionnaire. This questionnaire has 7 questions on the five Likert scale type. The scores are summed to obtain a final score (from 7 to 35). A score of less than 13 indicates good adherence, 13-17 a moderate adherence, and higher than 17 a poor GFD adherence [11].

Kaiser-Meyer-Olkin (KMO) test and Bartlett's test of sphericity were evaluated to confirm sample adequacy for elicitation of the factors. Principal axis analysis 
followed by a varimax rotation was used to test the factor constructs of all the seven items.

CFA was conducted to assess the goodness of fit between a hypothesized model provided in Leffler et al. study and the data obtained from 100 celiac patients in the present study who did not participate in the EFA. Chi-square, root mean error of approximation (RMSEA), comparative fit index (CFI), normed fit index (NFI), Tucker-Lewis index (TLI), and standardized root mean squared residual (SRMR) were measured. The acceptable values were Chi-square $p$-value $>0.05, \mathrm{RMSEA}<0.08$, TLI \& NFI $>0.9$, SRMR $<0.08$.

\section{Assessment of convergent validity}

For assessing convergent validity, the level of anti-tissue transglutaminase immunoglobulin A (anti-t-TG-IgA) was measured as a serological test of GFD adherence using AESKULISA $^{\bullet}$ tTG new generation kit (code:3503; Wendelsheim Germany). According to Kit instruction, the levels of less than $12 \mathrm{U} / \mathrm{ml}$ were considered good adherence, $12-18 \mathrm{U} / \mathrm{ml}$ a moderate adherence, and $>18 \mathrm{U} / \mathrm{ml}$ a poor adherence. The correlation between the adherence level obtained by Pv-CDAT and IgA anti-tTG was assessed by the Kendall-tau correlation test.

\section{Assessment of the reliability}

The internal consistency was measured through Cronbach's alpha. Besides, the ceiling and flooring effect is measured and values lower than $20 \%$ were considered acceptable. For calculating internal consistency, the mean scores of 130 questionnaires were used.

Test-retest reliability was assessed on 26 random samples of patients who completed the questionnaire 2 weeks apart. The Intraclass correlation coefficient (ICC) was used for analysis.

\section{Results}

In the present study, 230 celiac patients participated in the psychometric study of the Pv-CDAT scale. The mean age of participants was $36.36 \pm 12.90$ years and $61.7 \%$ of them were female. The mean disease duration was $4.26 \pm 4.89$ years. Other baseline characteristics of the participants are provided in Table 1.

The CVI, CVR, and impact score of the Pv-CDAT were $0.97,0.95$, and 4.61 respectively (Table 2 ).

As shown in Table 3, using factor analysis, three significant factors were extracted that account for $61 \%$ of the variance. The results of the KMO and Barlett sphericity test showed the model adequacy (KMO: 0.70 and Bartlett's test of sphericity $p$-value $<0.001)$. The first factor included questions 1 and 2, the second factor included questions 3,4 , and 5 and the third factor included questions 6 and 7.
Table 1 Baseline characteristics of celiac patients who participated in psychometrics properties assessment $(n=230)$

\begin{tabular}{ll}
\hline Variable & Mean \pm SD \\
\hline Age (years) & $36.36 \pm 12.90$ \\
Disease duration (Years) & $4.26 \pm 4.89$ \\
Frequency (\%) & \\
$\quad$ Sex (M:F) & $88(38.26) / 142(61.73)$ \\
Married & $166(72.17)$ \\
Positive family history of celiac & $14(6.08)$ \\
Education level & \\
$\quad$ Illiterate & $64(27.82)$ \\
$\quad$ High school & $159(69.13)$ \\
$\quad$ University & $7(3.01)$ \\
Anti-t-TG-IgA & \\
$\quad<12$ & $95(41.3)$ \\
$\quad$ 12-18 & $73(31.7)$ \\
$\quad$ 18 & $62(26.9)$ \\
\hline
\end{tabular}

Anti-t-TG-IgA Anti-tissue-transglutaminase-lgA

Figure 1 shows the results of the confirmatory factor analysis. According to these results, the three-factor model had acceptable fitness (Chi-square $p$-value: 0.74, RMSEA: 0.001 [95\% CI: 0.001-0.083], CFI: 1, SRMR: 0.04, and coefficient of determination: 0.78).

At the stage of determining convergent validity, the correlations between CDAT categories and antitTG categories was statistically significant $(r=0.53$; $P<0.001)$.

The Floor and ceiling effects were 3.1 and $0.4 \%$ respectively. The Cronbach alpha and ICC of the questionnaire were 0.71 and 0.78 [0.31-0.89].

\section{Discussion}

CDAT questionnaire is easy to use, fast, and valid tool for evaluating the adherence to the GFD [11]. Previously, two other questionnaires including the Biagi score (four questions) [16] and the theory of planned behavior (TPB) questionnaire (19 questions) [17] were developed for assessing GFD adherence in celiac patients. Considering that the CDAT with a limited number of questions provided the widest evaluation and it is used frequently in different research, we selected this questionnaire for translation [15]. Leffler et al. showed that it has higher sensitivity and specificity compared with serological tests in assessing GFD compliance. In this study, we translated this questionnaire into Persian and evaluated the psychometric properties of it in celiac patients. According to the results, the Pv-CDAT had good content validity, internal consistency, and test-retest reliability. Previously, only the psychometric 
Table 2 The results for the content and face validity of Persian version of CDAT questionnaire

\begin{tabular}{|c|c|c|c|}
\hline Items & $\mathrm{CV}^{*}$ & $C V R^{* *}$ & $1 S^{* * *}$ \\
\hline Have you been bothered by low energy level during the past 4 weeks? & 1 & 1 & 4.90 \\
\hline Have you been bothered by headaches during the past 4 weeks? & 0.97 & 0.82 & 4.20 \\
\hline I am able to follow a GFD when dining outside my home & 1 & 1 & 4.90 \\
\hline Before I do something I carefully consider the consequences & 0.93 & 0.82 & 4.18 \\
\hline I do not consider myself a failure & 0.90 & 1 & 4.09 \\
\hline How important to your health are accidental gluten exposures? & 1 & 1 & 5 \\
\hline Over the past 4 weeks, how many times have you eaten foods containing gluten on purpose? & 1 & 1 & 5 \\
\hline The mean of whole questionnaire & 0.97 & 0.95 & 4.61 \\
\hline
\end{tabular}

CVI Content validity index, CVR Content validity ratio, IS Impact score, GFD Gluten-free diet

*values $>0.56$ are acceptable; *** values $>0.79$ are acceptable; ${ }^{* * *}$ values $>1.5$ are acceptable

properties of the English [11] and Spanish [15] versions had been studied. The Spanish version of the questionnaire had moderate internal consistency [15]. The internal consistency of the final English questionnaire was not assessed. However, the prefinal questionnaire had high internal consistency (Cronbach $\alpha:$ 0.80) [11]. Besides, we showed high test-retest reliability of the Persian version which is in accordance with the results of the original English version (Pearson r: 0.82) [11].

The Pv-CDAT had CVI of 0.97 and all questions had the CVI equal or higher than 0.9. All questions had acceptable CVI according to the Lawshe Table (CVI > 0.56). In addition, CVR of the Pv-CDAT was 0.95 and all questions had CVR $\geq 0.82$. The impact score of the PvCDAT was 4.61 and all questions had IS higher than the minimum acceptable score [18].

Considering the results of factor analysis, the PvCDAT comprised three factors that confirm the structure of the English version both in the number of factors and their combination. This supports the construct validity of this questionnaire. The Spanish version of the questionnaire also fitted well with those originally proposed by Leffer et al. [15]. Considering that in both versions, Spanish and Persian, the number of items kept similar to that of the original questionnaire, the good construct validity is expected.

We also checked the correlation between the results of the CDAT and anti-tTG-IgA test and showed that these two tests were highly correlated. Previously, Leffler et al. have reported a high correlation between CDAT score and anti-tTG-IgA titer [11]. This correlation was not studied in the Spanish version of CDAT [15]. Although anti-tTG-IgA was not the best measurement to assess the adherence to GFD [19], it is routinely used for this purpose.

The results of this study should be interpreted considering the limitation of the present study. We just tested the questionnaire on the East Azerbaijan population, this may normally restrict the generalization of its results. Besides, we assessed convergent validity by analyzing the correlation between the score of the CDAT questionnaire and anti-tTG-IgA. As mentioned before, this test is not the gold standard to check GFD adherence. So, it is suggested that future studies consider the patients in different populations and also evaluated the correlation between the Pv-CDAT and other tests such as expert evaluation of adherence.

Table 3 Results of Exploratory Factor analysis of Pv-CDAT $(n=130)$

\begin{tabular}{lcc}
\hline Items & Factor 1 & Factor 2 \\
\hline Have you been bothered by low energy level during the past 4 weeks? & 0.67 & 0.55 \\
Have you been bothered by headaches during the past $\mathbf{4}$ weeks? & 0.63 \\
I am able to follow a GFD when dining outside my home & 0.42 \\
Before I do something I carefully consider the consequences & 0.40 \\
I do not consider myself a failure & 0.45 \\
How important to your health are accidental gluten exposures? & 0.43 \\
Over the past $\mathbf{4}$ weeks, how many times have you eaten foods containing gluten on purpose? & \\
\hline Extraction Method: Principal Axis Factoring. Rotation Method: Varimax with Kaiser Normalization &
\end{tabular}




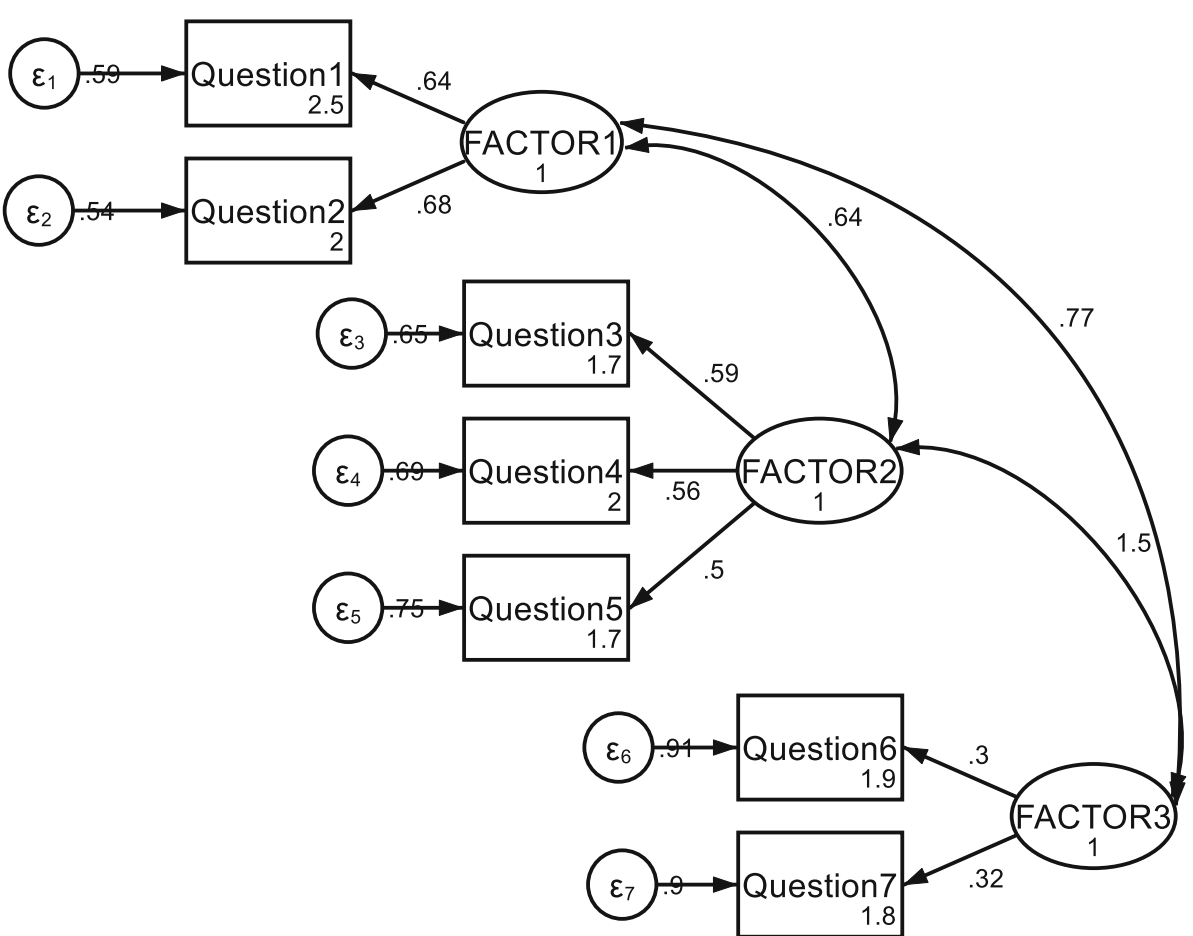

Fig. 1 Results of Confirmatory Factor analysis of the Pv-CDAT $(n=100)$

\section{Conclusions}

In conclusion, the results of the present study showed that the Pv-CDAT questionnaire had high validity, reliability, and internal consistency. Considering that compared with other methods, this questionnaire is easier to use, it can be applied for assessment of the level of adherence to GFD in adult celiac patients in Iran. In addition, in the pandemic situation like COVID-19, the questionnaires can be used to "tele-monitor" patients.

\section{Supplementary information}

Supplementary information accompanies this paper at https://doi.org/10 1186/s12876-020-01396-8.

Additional file 1: Table S1. The Persian version of the CDAT (Pv-CDAT) questionnaire.

\section{Authors' contributions}

ZN was responsible for the conception and design of the study. MSh, ZS, ZAN were responsible for the data acquisition. SGh, MAJ were responsible for data analysis and interpretation. ZN drafted the manuscript; all other authors revised and commented on the draft. All authors read and approved the final version of the manuscript.

\section{Funding}

This project was supported by a grant from Liver and gastrointestinal diseases research center, Tabriz University of medical sciences [grant number 62026]. The role of the funding: designing of the study and data collection.

\section{Availability of data and materials}

The datasets supporting the conclusions of this research are included in the article.

\section{Ethics approval and consent to participate}

The present study was approved by the Ethics Committee of Tabriz University of medical sciences (IR.TBZMED.REC.1398.244). Written informed consent was obtained from all participants.

\section{Consent for publication}

Not applicable.

CDAT: Celiac disease adherence test; Pv-CDAT: Persian version of celiac disease adherence test; CVR: Content validity ratio; CVI: Content validity index; IS: Impact score; GFD: Gluten-free diet; CD: Celiac disease; Anti-t-TGIgA: Anti-tissue transglutaminase immunoglobulin A; RMSEA: Root mean squared error of approximation; CFI: Comparative fit index:

SRMR: Standardized root mean squared residual

\section{Acknowledgments}

The authors wish to thank Dr. D. A Leffler for his permission and help in conducting this study. We are also grateful to the East Azerbaijan celiac patients for participating in the study.

\section{Competing interests}

Authors declare no conflict of interest.

\section{Author details}

${ }^{1}$ Liver and gastrointestinal diseases research center, Tabriz University of medical sciences, Tabriz, Iran. ${ }^{2}$ Road Traffic Injury Research Center, Department of Epidemiology and Biostatistics, Faculty of Health, Tabriz University of Medical Sciences, Tabriz, Iran. ${ }^{3}$ Medical Education Research Centre, Health Management and Safety Promotion Research Institute, Tabriz University of Medical Sciences, Tabriz, Iran. ${ }^{4}$ Student research committee, Tabriz University of medical sciences, Tabriz, Iran. 
Received: 18 March 2020 Accepted: 22 July 2020

Published online: 29 July 2020

\section{References}

1. Serena G, Lima R, Fasano A. Genetic and environmental contributors for celiac disease. Curr Allergy Asthma Rep. 2019;19(9):40.

2. Soldavini J. Krause's food \& the nutrition care process. J Nutr Educ Behav. 2019;51(10):1225.

3. Ahadi Z, Shafiee G, Razmandeh R, Keshtkar A-A, Sani MN, Azemati B, Sanaei M, Heshmat R. Prevalence of celiac disease among the Iranian population: a systematic review and meta-analysis of observational studies. Turk J Gastroenterol. 2016;27(2):122-8

4. Niewinski MM. Advances in celiac disease and gluten-free diet. J Am Diet Assoc. 2008;108(4):661-72.

5. Kurppa K, Lauronen O, Collin P, Ukkola A, Laurila K, Huhtala H, Mäki M, Kaukinen K. Factors associated with dietary adherence in celiac disease: a nationwide study. Digestion. 2012;86(4):309-14.

6. Villafuerte-Galvez J, Vanga R, Dennis M, Hansen J, Leffler D, Kelly C, Mukherjee R. Factors governing long-term adherence to a gluten-free diet in adult patients with coeliac disease. Aliment Pharmacol Ther. 2015:42(6): 753-60.

7. Nikniaz Z, Farhangi MA, Hosseinifard H, Nikniaz L. Does a gluten-free diet increase body mass index and lipid profile in celiac patients? A systematic review and meta-analysis. Mediterr J Nutr Metab. 2019;12(4):341-52.

8. Zarkadas M, Case S. Celiac disease and the gluten-free diet: an overview. Top Clin Nutr. 2005:20(2):127-38.

9. Hall N, Rubin G, Charnock A. Systematic review: adherence to a gluten-free diet in adult patients with coeliac disease. Aliment Pharmacol Ther. 2009; 30(4):315-30.

10. Leffler D, Edwards George J, Dennis M, Cook E, Schuppan D, Kelly C. A prospective comparative study of five measures of gluten-free diet adherence in adults with coeliac disease. Aliment Pharmacol Ther. 2007; 26(9):1227-35.

11. Leffler DA, Dennis M, Edwards George JB, Jamma S, Magge S, Cook EF, Schuppan D, Kelly CP. A simple validated gluten-free diet adherence survey for adults with celiac disease. Clin Gastroenterol Hepatol. 2009;7(5):530-6 536.e531-532.

12. Fueyo-Diaz R, Magallon-Botaya R, Gascon-Santos S, Asensio-Martinez A, Palacios-Navarro G, Sebastian-Domingo JJ. The effect of self-efficacy expectations in the adherence to a gluten free diet in celiac disease. Psychol Health. 2019;35(6):1-16.

13. Hughey JJ, Ray BK, Lee AR, Voorhees KN, Kelly CP, Schuppan D. Selfreported dietary adherence, disease-specific symptoms, and quality of life are associated with healthcare provider follow-up in celiac disease. BMC Gastroenterol. 2017;17(1):156.

14. Johansson K, Norstrom F, Nordyke K, Myleus A. Celiac dietary adherence test simplifies determining adherence to a gluten-free diet in Swedish adolescents. J Pediatr Gastroenterol Nutr. 2019:69(5):575-80.

15. Fueyo-Díaz R, Gascón-Santos S, Asensio-Martínez Á, Sánchez-Calavera MA, Magallón-Botaya R. Transcultural adaptation and validation of the celiac dietary adherence test. A simple questionnaire to measure adherence to a gluten-free diet. Rev Esp Enferm Dig. 2016;108(3):138-44.

16. Biagi F, Andrealli A, Bianchi PI, Marchese A, Klersy C, Corazza GR. A glutenfree diet score to evaluate dietary compliance in patients with coeliac disease. Br J Nutr. 2009;102(6):882-7.

17. Sainsbury K, Mullan B. Measuring beliefs about gluten free diet adherence in adult coeliac disease using the theory of planned behaviour. Appetite. 2011;56(2):476-83.

18. Lawshe $\mathrm{CH}$. A quantitative approach to content validity 1. Pers Psychol. 1975;28(4):563-75.

19. Pyle GG, Paaso B, Anderson BE, Allen D, Marti T, Khosla C, Gray GM. Lowdose gluten challenge in celiac sprue: malabsorptive and antibody responses. Clin Gastroenterol Hepatol. 2005;3(7):679-86.

\section{Publisher's Note}

Springer Nature remains neutral with regard to jurisdictional claims in published maps and institutional affiliations.

\section{Ready to submit your research? Choose BMC and benefit from:}

- fast, convenient online submission

- thorough peer review by experienced researchers in your field

- rapid publication on acceptance

- support for research data, including large and complex data types

- gold Open Access which fosters wider collaboration and increased citations

- maximum visibility for your research: over $100 \mathrm{M}$ website views per year

At BMC, research is always in progress.

Learn more biomedcentral.com/submissions 